\title{
Midwives' knowledge of COVID 19 and pregnancy in four maternity units in Brazzaville in 2021
}

\author{
Summary \\ Purpose: To evaluate midwives' knowledge of Covid 19 and Pregnancy. \\ Materials and methods: This was a knowledge analytical study. Midwives working in \\ delivery units and outpatient clinics were included. The variables were focused on socio- \\ demographic and professional aspects, general information on Covid-19, the clinical and \\ biological manifestations, the prevention of corona virus transmission and the prevention \\ of mother-to-child transmission.
}

Results: Out of 82 respondents, $73(89.1 \%)$ were secondary school graduates, working mainly in Talangai Hospital. The media was the source of information for 78 (95.1\%); Covid 19 is a viral infection $78(95.1 \%)$; the route of contamination was respiratory 79 (96.3\%) and transplacental $16(19.5 \%)$ of respondents. The clinical signs were: fever $76(92.7 \%)$, cough $77(93.9 \%)$ and dyspnea $77(93.9 \%)$ of the respondents. Biological diagnosis was done by RDT (rapid diagnosis test) 73 (89, 1\%), completed by PCR confirmation $43(52.4 \%)$ of the respondents. Prevention methods: hand washing several times a day $72(87,8 \%)$ and alternative by disinfectant gel $75(91,5 \%)$; lifting the fold of the elbow when sneezing or coughing $76(89 \%)$; used handkerchief thrown in the trash 70 $(85,4 \%)$ of the respondents; out of 3 preventive measures in the labour room, $20(23,4 \%)$ answered correctly, $48(58,5 \%)$ gave only 1 to 2 correct answers and $14(17 \%)$ did not identify any measure. The overall knowledge of midwives on Covid 19 was insufficient 25 $(30.5 \%)$, average $52(63.4 \%)$, good $5(6.1 \%)$ of the respondents. For the factors that can influence the level of knowledge, there is no link between the level of knowledge and the socio-professional characteristics of the midwives (Chi2 test: P-value $>5 \%$ ). However, the fact of working at the CHUB could have a slight influence (sensitive P-value close to 95\%).

Conclusion: There is a need to diversify sources of information for an improvement of knowledge in order to place the midwife at the top of the medical news.

\author{
Volume 5 Issue 6 - 202I
}

\author{
Jean Alfred Mbongo,' Gickelle Bintsene \\ Mpika,' Hermann N'dinga, ${ }^{2}$ Norcia Itoua,' \\ Jean Daniel Mahoungou, ${ }^{3}$ Serge Parfait \\ Koko, ${ }^{4}$ Leon Hervé Iloki' \\ 'Gynecology and obstetrics Unit, CHU Brazzaville, Brazzaville, \\ Congo \\ ${ }^{2}$ Maternity, Reference Hospital of Talangai, Brazzaville, Congo \\ ${ }^{3}$ Maternity, Mother and Child Specialized Hospital Blanche \\ Gomez, Brazzaville, Congo \\ ${ }^{4}$ Maternity, Central Hospital of Armies, Brazzaville, Congo
}

Correspondence: Jean Alfred Mbongo, Gynecology and obstetrics Unit, CHU Brazzaville, Brazzaville, BP: 32, Brazzaville Congo, Congo, Tel 00242 05531912,

Email mbongojalf@gmail.com

Received: October 12, 2021 | Published: November 18, 202 |

Keywords: Covid 19 pregnancy, knowledge, Midwife, Brazzaville

\section{Introduction}

The recent pandemic of COVID-19 has led to an unprecedented global health crisis. It is a new Coronavirus identified in the city of Wuhan, Hubei province in China in December 2019, in patients who presented with unexplained severe pneumonitis. The disease is caused by the virus initially called COV-2019, then SARS-COV-2 by the international virus taxonomy committee, in January 2020, World Health Organization (WHO) assigns the name COVID -19. ${ }^{1}$ As of September 4, 2021 according to WHO, 230,147,174 cases confirmed worldwide, with 4,720,430 deaths. However in Congo, the Ministry of Health and Population reports 13493 confirmed cases, and 211 deaths of the coronavirus disease as of August 19, 2021.

The physiological, immunological and cardiopulmonary changes associated with pregnancy are likely to make pregnant women more vulnerable to infectious complications and respiratory pathologies. ${ }^{2}$ For some of the authors, there is no risk of maternal-fetal transmission of Covid $19,3,4,5$ while for others there is the possibility of vertical transmission. ${ }^{6}$ Covid 19 infection has spread rapidly in the world, however there is an ambiguity of its impact on pregnancy; due to the lack of scientific data, obstetricians have adapted their practice based on pragmatic conduct.

The midwife, because of her central place in obstetrical care, has a primordial role in terms of information, care and orientation of pregnant women. In a developing country such as ours, where the health system is very fragile, health professionals need information on Covid 19 in order to develop strategies or new skills to deal with it. AS such we wanted to evaluate the knowledge of midwives about Covid 19 associated with pregnancy and determine their perception of the response to the pandemic in the health facilities of Brazzaville.

\section{Methodology}

This was an analytical study of knowledge, which took place from July $1^{\text {st }}$ to $31^{\text {st }} 2021$, at the Hospital and University Centre of Brazzaville (CHU B), and the reference hospitals of Brazzaville (Hospital of Talangai, Central Hospital of the Armed Forces, Specialized Hospital Mother and Child Blanche Gomez). The study population consisted of midwives working in the hospitals selected for the study. Midwives with informed consent, practicing in delivery units and outpatient clinics with at least 12 months of professional experience were included. Midwives who were absent during the study period were excluded.

The sampling method used was non-probabilistic. Thus, we proceeded with a simple and exhaustive sampling, while taking into account the study period. The sampling was of the probabilistic type, the size of which was obtained by reasoned choice through saturation. The sociodemographic and professional variables of the midwives and those related to their knowledge of the viral infection, the clinical 
and biological signs. We also highlighted the prevention of corona virus transmission through barrier measures: hand washing, use of hydro-alcoholic gel, bib, precautions during contact with the infected person, and the way of coughing, prevention during childbirth and breastfeeding (Table 1). The level of knowledge was assessed using the method of Bruno De Finetti, ${ }^{7}$ improved by Dieudonné Leclercq. ${ }^{8}$ Table 2 represents the level of knowledge of the midwives.

Table I Knowledge Rating Grid

\begin{tabular}{lll}
\hline Area to be explored & Number of variables & Scoring \\
\hline General information & at least 0 & \\
& 2 à 4 & I \\
& 5 à 6 & 2 \\
Diagnosis & At least I & 0 \\
& 2 à 4 & 1 \\
& 5 à 6 & 2 \\
7 à 8 & 3 \\
Prévention & At least I & 0 \\
& 2 à 5 & 1 \\
6 à 9 & 2 \\
\hline
\end{tabular}

Table 2 Midwives' level of knowledge

\begin{tabular}{lll}
\hline Level & Points & Title of knowledge level level \\
\hline Level I & 0 à I & Wrong \\
Level 2 & 2 à 4 & Insufficient \\
Level 3 & 5 à 6 & Average \\
Level 4 & 5 à 6 & Good \\
\hline
\end{tabular}

Wrong $=25 \%$ correct answers

Insufficient $=50 \%$ correct answers

Average $=70 \%$ correct answers

Good $=$ more than $70 \%$ correct answers

\section{Data analysis}

The data were entered using a data entry mask developed on the CSPRO version 7.5 software. The analysis was done with SPSS version 25.0 and microsoft Excel was used to improve the tables and graphs. We calculated percentages for qualitative or categorical variables and means, standard deviation and median for quantitative variables. In order to establish the influence of the different variables on each other, bivariate and multivariate analyses were performed. The Chi- 2 test and the odds ratio (OR) with its $95 \%$ confidence interval were used to assess the association between categorical variables and risk determination respectively. The Student's t test and the Mann Whitney test were used for the association between a qualitative and quantitative variable. Thus, in order to appreciate the influence of socio-demographic and professional characteristics on knowledge, we made cross-tabulations with the levels of knowledge performance (satisfactory and unsatisfactory) resulting from the grouping of the starting level of knowledge variable (cf. Table II). All this, in order to obtain the odd ratios with the $95 \%$ confidence interval, then the influence of socio-demographic and professional characteristics on knowledge was brought out by the simple logistic regression method.
The level of knowledge was the dependent variable and the sociodemographic and professional characteristics were the independent variables.

\section{Results}

Of the questionnaire submitted to the midwives, 82 met the inclusion criteria. Table 3 shows the socio-demographic and professional characteristics. Most of them were midwives with a secondary level of education, working mainly at the Talangai Referral Hospital. Each respondent had heard of Covid 19, of which $78(95.1 \%)$ characterized it as a viral infection and for $64(78 \%)$ of them transmission was not possible via breastfeeding. The sources of information were the media 78 cases $(95.1 \%)$, seminars $3(3.7 \%)$ and conferences $1(1.2 \%)$. For the contamination route, the respondents answered the respiratory route in $79(96.3 \%)$ cases, transcutaneous route in 42 cases (51.2\%) and the ascending route (transplacental) was not a route of contamination for 66 respondents $(80.5 \%)$. The clinical signs were fever in 76 cases $(92.7 \%)$, cough in 77 cases $(93.9 \%)$ and dyspnea in 77 cases $(93.9 \%) .65(79.3 \%)$ of the respondents diagnosis was done by rapid diagnosis test and for $43(52.4 \%)$ was confirmed by PCR thereafter.

Table 3 Socio-professional characteristics of midwives

\begin{tabular}{lll}
\hline & $\mathbf{n}$ & $\%$ \\
\hline Level of study & 5 & 6,1 \\
-Primary & 24 & 29,3 \\
- secondary I & 49 & 59,8 \\
- secondary 2 & 4 & 4,9 \\
-Superior & & \\
Health structure & 14 & 17,1 \\
-Blanche Gomez & 15 & 18,3 \\
-CHUB & 36 & 43,9 \\
-Hôpital de Talangai & 17 & 20,7 \\
- Central Hospital of Armies & Mean (year) & Médian (min- max) \\
Seniority & $11,1 \pm 8,9$ & 10,0 (0-53) \\
-At midwife grade & $9,0 \pm 9,6$ & $7,0(0-64)$ \\
-In the health facility &
\end{tabular}

For general information on the Covid 19

In terms of preventive measures, $72(87.8 \%)$ of the respondents were in favor of washing their hands several times a day, and 75 $(91.5 \%)$ used disinfectant gel as an alternative to hand washing. $89 \%$ of the respondents felt that it was necessary to lift their elbows when sneezing or coughing in order to block the spread of droplets, and $85.4 \%$ of the respondents threw away the used handkerchief in the garbage immediately after usage. Regarding the 3 preventive measures to be adopted when faced with a confirmed Covid positive pregnancy in the labour room, 20 (23.4\%) answered correctly, 48 (58.5\%) gave only 1 or 2 correct answers and $14(17 \%)$ did not identify any measure.

For $47(57.3 \%)$ of the respondents women could give birth vaginally, meanwhile for 77 (93.9\%) of the respondent both women and practitioner had to wear a face mask during delivery obligatorily and wearing gloves during the examination of the woman for 79 (96.3\%) respondents. Most of the respondents were in favour of maternal breastfeeding ( 68 cases or $82.9 \%$ ), provided that the mother 
was required to wear a face mask during breastfeeding. The midwives' overall knowledge of Covid 19 was insufficient in 25 cases $(30.5 \%)$, average in 52 cases $(63.4 \%)$, good in 5 cases $(6.1 \%)$, however they had a good knowledge score on the diagnosis and half of them had good notions on the prevention of Corona 19; as represented in Table 4. For the research on factors that can influence the level of knowledge, there is no link between the level of knowledge and the socio-professional characteristics of midwives (Chi-square test: $\mathrm{P}$-value $>5 \%$ ). However, working at CHUB might have a slight influence (sensitive P-value close to $95 \%$ ). The illustration was done on Table 5.

Table 4 Midwives' knowledge levels about Corona 19

\begin{tabular}{|c|c|c|c|}
\hline & Rating score & $\mathbf{n}$ & $\%$ \\
\hline \multicolumn{4}{|c|}{ Level of global knowledge } \\
\hline - Poor & 0 à 1 & - & - \\
\hline - Insufficient & 2 à 4 & 25 & 30,5 \\
\hline - Medium & 5 à 6 & 52 & 63,4 \\
\hline - Good & 7 à 8 & 5 & 6,1 \\
\hline Mean Score & $5,09 \pm 8,9$ & & \\
\hline Median Score & (QI-Q3)5 (4-6) & & \\
\hline \multicolumn{4}{|c|}{ Information knowledge } \\
\hline \multicolumn{4}{|c|}{ - General knowledge } \\
\hline 0 & At least I & - & - \\
\hline I & 2 à 4 & 40 & 48,8 \\
\hline 2 & 5 à 6 & 42 & 51,2 \\
\hline \multicolumn{4}{|c|}{ - Knowledge of diagnosis } \\
\hline 0 & At least I & 4 & 4,9 \\
\hline I & 2 à 4 & 67 & 81,7 \\
\hline 2 & 5 à 6 & II & 13,4 \\
\hline 3 & 7 à 8 & - & - \\
\hline \multicolumn{4}{|c|}{-Knowledge of prévention } \\
\hline 0 & At least I & - & - \\
\hline I & 2 à 4 & 2 & 2,4 \\
\hline 2 & 5 à 6 & 38 & 46,3 \\
\hline 3 & 7 à 8 & 42 & $5 I, 2$ \\
\hline
\end{tabular}

Table 5 Influence of socio-professional characteristics on the level of knowledge of midwives on Covid 19

\begin{tabular}{|c|c|c|c|c|c|c|c|c|}
\hline & \multirow[b]{2}{*}{$\mathbf{n}$} & \multicolumn{3}{|c|}{ not satisfying } & \multicolumn{3}{|c|}{ Satisfactory } & \multirow{2}{*}{$\begin{array}{l}\text { IC95\% } \\
\text { Sup }\end{array}$} \\
\hline & & $\%$ & $\mathbf{n}$ & $\%$ & $\mathbf{P}$ & OR & Inf & \\
\hline \multicolumn{9}{|l|}{ Health facility } \\
\hline -Blanche Gomez & 6 & 24 & 8 & 14 & 0,815 & $\mathrm{I}, 185$ & 0,285 & 4,922 \\
\hline$-\mathrm{CHU} B$ & 2 & 8 & 13 & 22,8 & 0,052 & 5,778 & 0,987 & 33,828 \\
\hline Hôpital de Talangaï & 9 & 36 & 27 & 47,4 & 0,114 & 2,667 & 0,791 & 8,987 \\
\hline Central Hospital of Armies & 8 & 32 & 9 & 15,8 & - & - & - & - \\
\hline \multicolumn{9}{|l|}{ Level of midwives } \\
\hline -Primary & 1 & 4 & 4 & 7 & 0,858 & 1,333 & 0,057 & 31,121 \\
\hline -Secondary I & 10 & 40 & 14 & 24,6 & 0,534 & 0,467 & 0,042 & 5,166 \\
\hline -Secondary 2 & 13 & 52 & 36 & 63,2 & 0,947 & 0,923 & 0,088 & 8,987 \\
\hline -Superior & I & 4 & 3 & 5,3 & - & - & - & - \\
\hline
\end{tabular}


Table Continued...

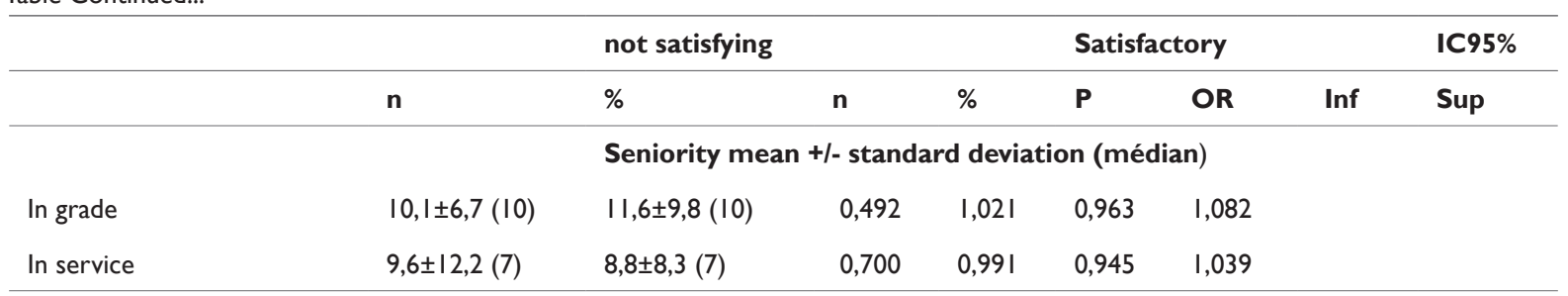

\section{Discussion}

Our sample of 82 midwives seems insufficient, which may be a bias in the study, as it does not claim to be representative of all midwives working in the above-mentioned health facilities. The strong reluctance or lack of interest in the study would be related to the feeling of being evaluated through this study, and the persuasiveness of the interviewer. The reluctance to participate in the Covid 19 survey has already been reported in the literature. ${ }^{9}$ In the past, from secondary level I or II, through professional examinations, one could access the grade of midwife, which would explain the large number of respondents with these levels, currently access to the grade of midwife is governed by the LMD (Licence Master Doctorat) system. The higher level of the midwife does not seem to have any influence on the level of knowledge about Covid 19, certainly because of the emerging nature of the disease. Indeed, even some reliable sources such as the World Health Organization (WHO), disseminate information that end up becoming untruths, such as the information that young people run a low risk of becoming Infected with Covid 19, which could give a false assurance.${ }^{10}$ However, some authors report that, the education of the respondents could explain the good level of knowledge on Covid 19. ${ }^{11}$

The main source of information for the respondents was the media, which has continued to play a key role in raising awareness of the virus since its spread. ${ }^{12}$ The respiratory route was clearly identified as the mode of contamination of the virus ( $96.3 \%$ of respondents). According to some authors, pregnant women are particularly exposed to infectious pneumopathies because of the physiological changes specific to pregnancy (elevation of diaphragm, increase oxygen consumption and respiratory tract edema).${ }^{13}$ Most of the authors, on the other hand, do not find any particularity of the SARS-COV2 infection in pregnant women compared to the general population..$^{14,15}$ The impact of the transcutaneous contact in the transmission was recognized by only half of the respondents. The impact of transcutaneous contact in transmission was only recognized by half of the respondents ${ }^{14,15}$ it is therefore important to make the link between the environment, the hand and its contact with the nose (respiratory tract). it is therefore worthwhile to clean and disinfect frequently objects, surfaces that may be contaminated such as door handles, taps, mobile phones, keyboards and computer mice. ${ }^{16}$

Vertical transmission was not recognized by $80.5 \%$ of the respondents. In fact this is rebut by many authors. ${ }^{17,18,15,16}$ The absence of the virus in the amniotic fluid, cord blood and newborn smear samples would be proof of this. ${ }^{16}$ The clinical (cough, fever, breathing difficulties) and biological (rapid test after nasal swab, PCR confirmation) manifestations most characteristic of covid19 were often identified by the respondents and are similar to those found in the general population. However, some authors report that fever is less frequent in pregnant women. ${ }^{2}$ Barrier measures and personal protective equipment are known to the respondents, but for them to be effective there may be a problem of their availability and their proper use. Some authors report that these measures should be applied more to pregnant women who would be more vulnerable. ${ }^{18}$
Special precautions should be taken among health care personnel to minimize the number of people in contact with an infected patient. ${ }^{18}$ The management of an epidemic such as Covid 19 in our facilities or in Africa and in general is an even more delicate situation due to the limited number of human resources. ${ }^{19}$ There is a lack of knowledge about the preventive measures to be taken in the labour room in the presence of a Covid-positive pregnant woman. If it were only a question of midwives working in the labor ward, ignorance of all preventive measures is a danger to oneself and to others. This was the case for health personnel, whereas a study of the general population in Dakar reported that the people interviewed had good knowledge of the signs, risks of transmission and preventive measures; but despite efforts to raise awareness, false rumours are on the increase. ${ }^{20}$

Slightly more than half of those questioned were in favour of vaginal delivery, with compliance with barrier measures. However, in the case of Covid 19, delivery should essentially take place by vaginal delivery outside of purely obstetrical indications, as reported by several authors. ${ }^{15,2}$ Breastfeeding has been widely encouraged, with respect of barrier measures in our survey. Indeed, to date, no case of breastfeeding-related transmission has been described and the virus has not been found in breast milk. ${ }^{15,18}$ Midwives' overall knowledge of Covid 19 is still average, whereas the quality of care and patient safety approach should take into account the dimension of training and behavioural change of health professionals. ${ }^{18}$ There is no relationship between the level of knowledge and the socio-professional characteristics of midwives. Two years after the start of the Covid 19 pandemic, knowledge about infection in pregnant women is still fragmentary. Thus, the behavior of the general population will have an important impact on the evolution of the Corona virus pandemic, as human behavior is influenced by the knowledge and perceptions of individuals. ${ }^{21}$ Considering the small sample of female respondents evolving in the CHUB, and the main source of acquiring information about Covid 19 which is "the media", the workplace has no influence on knowledge. The influence on knowledge could be related to the level of development of new work methods, the acquisition and sharing of new knowledge with colleagues, the development of strategies or new know-how. ${ }^{22}$

\section{Conclusion}

The knowledge of practitioners such as midwives, when their main sources are the media, is unstable and incomplete, with the risk of misinformation. In order to improve the level of care and to adapt health structures to emerging diseases, it is necessary to encourage thematic staffs in the services, training seminars, and congresses.

\section{Acknowledgments}

None.

\section{References}

1. Bonny V, Maillard A, Mousseaux C, et al. Covid 19: Pathophysiology of a multifaceted disease. The Journal of Internal Medicine. 2020;41:375-389. 
2. Kouas S, Zoukar O, Khouloud Ikridih, et al. COVID-19 infection in pregnant women: a case report Covid-19 case. PAMJ. 2020;37(156):1-6.

3. Chen H, Guo J, Wang C, et al. Clinical charactéristics and intra uterine vertical transmission potential of covid 19 infection in nine pregnant women: a retropective review of medica 1 record. Lancet. 2020;395(10226):809-815.

4. Zeng L, Xia S, Yuan W. Neonatal-onset infection with SARS-COV2 in 33neonates born to mothers with Covid -19 in Wuhan China. JAMA Pediatr. 2020;174(7):722-725.

5. De Finetti B. Methods for discriminating levels of partial knowledge concerning a test item. Br J Math Stat Psychol. 1965;18(1):123-187.

6. Dieudonné Leclercq. Partial knowledge in the patient: why And how to measure it. Ther Patient Educ / Ther Patient Educ. 2009;1(2):S201-S212.

7. Miemane Abdou Oumarou, Las-Vegnas O, Nassir Messaadi. Studies of knowledge, attitudes and condom practices (CAPs1) in the community of health professionals during the coronavirus epidemic in Niamey. 2020.

8. Mamadou Macktar Mbacké Leye, Mamby Keita I, Oumar Bassoum. Knowledge, attitudes and practices of the population of the Dakar region on Covid 19. Public Health. 2020;32(5-6):1-13.

9. Ngoyi JM, Kabamba LN, Tabwé PN, et al. Knowledge, attitudes and practices related to SARS-COV2 (Covid 19) among students at the Institut Supérieur des Techniques Médicales de Lubumbashi. Rev de l'Infirmier Congolais. 2020;4(2):8-12.

10. World Health Organization. Coronavirus disease (Covid 19), advice to the public. Mthbusters Geneva WHO April. 2020.

11. Plaçais L, Richier Q. Covid 19: clinical, biological and radiological characteristics in adults, pregnant women and children. An update in the midst of the pandemic. Rev Med Int. 2020;41(5):308-318.
12. Chen $\mathrm{H}$, Guo J, Wang $\mathrm{C}$, et al. Clinical characteristics and intra uterine vertical transmission potencial of covid 19 infection in nine pregnant women :a retrospective review of medical record. Lancet. 2020;395(10226):809-815.

13. Masmejan S, Pomar Léo, Lepigeon K, et al. Covi19 and pregnancy. Rev Med Suisse. 2020;16:944-946.

14. Lapirre A, Fontaine G, Trmblay PL, et al. Corona virus disease (Covid 19): current knowledge Emergency care. 2020;1(1):13-19.

15. Government of Quebec. Information-for-pregnant-women.coronavirus (Covid 19). 2020

16. Yang H, Wang C, Poon L. Novel coronavirus infection in pregnancy. Ultrasound Obstet Gynecol. 2020;55(4):435-437.

17. Kouas S, Zoukar O, Khouloud Ikridch. Covid 19 infection in a pregnant woman about a case. PAMJ. 2020;37(156):1-6.

18. Hien H, Drabo M, Ouedraogo L, et al. Knowledge and practices of health professionals on the infectious risk associated with care: a study in a district hospital in Burkina Faso. Public Health. 2013;25(2):219-226.

19. Centre for Disease Control and Prevention. Covid 19 Pandemic: Contact tracing guidelines.

20. Mamadou Makhtar Mbake leyé, Ibrahima Mamby Keita, Oumar Bassoum. Knowledge, attitudes and practices of the population of the Dakar region on Covid 19. Public Health. 2020;32(5-6):1-13.

21. Geldsetzer P. Knowledge and perceptions of Covid 19 among the general population in the United States and the United Kingdom. A cross-sectional online survey March. 2020.

22. Miemane Abdou Oumarou, Las -Vergnas O, Nassir Messaadi. Study of knowledge, attitudes and condom practices (CAPs 1) in the community of health professionals during the coronavirus epidemic in Niamey. 2020. 